\title{
EL HOSPITAL DE LA ENCARNACIÓN DE ZAMORA EN EL SIGLO XVIII: REGLAMENTACIÓN Y EVOLUCIÓN ASISTENCIAL
}

\author{
María José PÉRez Álvarez \\ Universidad de León
}

Fecha de recepción: enero 2013

Fecha de aceptación: abril 2013

La oferta asistencial en la ciudad de Zamora experimentó notables cambios durante la Edad Moderna. La desaparición de un gran número de pequeños hospitales se compaginó con la creación de otros nuevos, concretamente, los de Sotelo, La Encarnación y Convalecientes ${ }^{1}$. El primero lo fundó D. Alonso de Sotelo, en el primer tercio del siglo XVI, y dejó elaborada buena parte de la normativa por la que debía regirse. Los otros dos se fundaron en la centuria siguiente, por D. Pedro Morán y D. Pedro de la Torre Guedexa, respectivamente, si bien este último no empezó a funcionar hasta la segunda mitad del siglo XVIII. A mediados de esa centuria, según las Respuestas Generales del Catastro del marqués de la Ensenada, además de los hospitales Sotelo y La Encarnación, prestaban servicio en aquella ciudad: El Caño, San Lázaro y la Casa de Misericordia. Estos tres poseían unas rentas mucho más modestas que los anteriores y respondían a un modelo de fundación plenamente medieval, por ejemplo, del primero de ellos sabemos que ofrecía a los pobres hospedaje «paja para dormir, lumbre para calentarse, vestido y, llegado el caso, asistencia mortuoria, costeando su entierro» ${ }^{2}$.

\footnotetext{
1. Este trabajo forma parte del proyecto de investigación titulado «Marginación y asistencia social en el Noroeste de la Península Ibérica durante el Antiguo Régimen», subvencionado por el Ministerio de Ciencia e Innovación (Ref. HAR 2010-17780).

2. Cerespo González, José y Mata Guerra, Juan Carlos (de la): «La vía de la Plata en la provincia de Zamora», Perona Larraz, José Luis (Dir.), Historia hospitalaria de la Vía de la Plata, Salamanca, 2009, pp. 213-273, p.226.
} 


\section{EL HOSPITAL DE LA ENCARNACIÓN}

En 1629 D. Pedro Morán Pereira elaboró la escritura fundacional del hospital de La Encarnación en la ciudad de Zamora, que sería inaugurado el 25 de marzo de $1678^{3}$. Para garantizar su viabilidad económica lo dotó con gran parte de su patrimonio y del que le había confiado su hermano, D. Isidro Morán, en $1602^{4}$. La circunstancia que lo empujó a instituir una fundación de esas características, según dejó expresado en su testamento, había sido el que «habiendo considerado la gran necesidad que hay en la ciudad de Zamora de que se curen los pobres y necesitados que hay en ella, y que la más de la gente que tiene es pobrísima y que por falta de albergue y cura se mueren o padecen largas enfermedades $\rangle^{5}$. No obstante, la decisión de D. Pedro no tuvo como únicos guías el ejercicio de la caridad y la preocupación por la salvación de su alma. Por encima, o al menos en un plano similar, estaría la falta de descendencia directa, que otorgara al linaje proyección histórica. Para mantener viva esa memoria mandó construir el hospital con una iglesia adosada, que sería el verdadero escenario propagandístico. En ella ordenó colocar los catafalcos de los hermanos Pereira, que, de esta forma, estarían presentes en todas las celebraciones religiosas.

Como patronos del hospital nombró a un representante del cabildo de la catedral, otro del regimiento y a los priores de los conventos de San Jerónimo y Santo Domingo, si bien, por motivos que ellos mismos dicen desconocer, este último dejó de asistir a las reuniones pocos años después de ponerse en funcionamiento el centro. Tres de esas instituciones también formaban parte de la dirección del hospital de Alonso de Sotelo. Se trataba del regimiento, cabildo y convento de Santo Domingo. Esa coincidencia iba más allá de las corporaciones, llegó a trasladarse a las personas y ambos establecimientos tenían, prácticamente, el mismo órgano directivo ${ }^{6}$. Circunstancia que los llevó a una intensa colaboración, desde compartir médico hasta asistirse económicamente.

3. Pocos días antes el patronato había nombrado al personal sanitario que se iba a encargarse de atender a los enfermos: un médico, un cirujano y un boticario. Seis meses después de la inauguración acordaron admitir sólo a diez pacientes, «para no andar alcanzados». Archivo de la Diputación de Zamora (A.D.Z.), Libo de Acuerdos del hospital de La Encarnación.

4. Ese patrimonio fue creciendo gracias a las limosnas y herencias de las que se benefició el centro. Por ejemplo, el arzobispo de Tarragona, que antes había sido obispo de Zamora, además de contribuir con diversa dádivas en el siglo XVIII, en su testamento le hizo una manda 1.000 reales. En 1765, D. José Nájera y D. Juan Ignacio de Vitoria, prebendado y cura de la catedral, respectivamente, dieron un donativo de 5.000 reales, cada uno. D. José Tesera, favoreció a la Obra Pía con un oficio perpetuo de merino y diversas viñas. También las clases populares y los militares contribuyeron a la prosperidad de la institución. Entre esos benefactores estuvieron D. Diego Molla, subteniente del primer batallón de inválidos de castilla, o Juan Porto, vecino de Zamora, ambos, fallecidos en el centro, lo dejaron como heredero de sus bienes. A.D.Z., Libros de Acuerdos del hospital de La Encarnación.

5. A.D.Z., Leg. 65 (1).

6. Por ejemplo, en 1749 formaban parte del patronato de La Encarnación: D. Alonso Varga, en representación del cabildo, D. Juan Félix de Salcedo, por el regimiento, y fray Bernardo de San Pedro, por los Jerónimos. Los dos primeros, junto al prior de Santo Domingo, fray Sebastián Rodríguez, eran también integrantes del de Sotelo. Esa duplicidad de cargos se repite, prácticamente, desde finales del siglo XVII hasta, al 
La función prioritaria del Hospital de La Encarnación era la atención médica y, al menos en primer término, no se contemplaba la asilar o de albergue, que había sido consustancial a la mayor parte de los establecimientos de este tipo. Siguiendo las disposiciones del fundador, estaba llamado a convertirse en un centro moderno, en el que cada enfermo disfrutaría de un aposento individual, con una cama de cordel, ventana y cerrado con una cortinilla. La salubridad y la prevención de contagios no era el objetivo de esta media, aunque sí su consecuencia; esa intimidad iba encaminada a proteger la identidad de los pobres vergonzantes?

Asociada a este hospital se hallaba la cofradía del Glorioso Arcángel San Rafael, surgida a mediados del siglo XVIII. Su finalidad, según recogen los estatutos de 1762, era «atender las necesidades espirituales de los pobres y el alivio de sus enfermedades y curación de ellas» ${ }^{8}$. Esa solidaridad para con los necesitados se prolongaba hasta la muerte, pues también se encargaban de dar cristina sepultura y celebrar las honras fúnebres de los que fallecían en la institución y eran enterrados en el camposanto.

Respecto a los asistidos, en el hospital de La Encarnación no sólo se curaron los pobres de la ciudad y los transeúntes, también los presos, militares y, desde comienzos del siglo XIX, los pobres recogidos por la Junta de Caridad. Estos dos últimos colectivos debían pagar por los servicios que allí recibían'. A mediados del siglo XVIII los responsables del hospital firmaron un acuerdo con la corona, en el que redactaban las condiciones para atender, al igual que en el hospital de Sotelo, a los militares que resultaran heridos o sufrieran alguna enfermedad ${ }^{10}$. No obstante, esos ingresos ya hacía años que venían siendo frecuentes, a pesar de las reticencias de los patronos ${ }^{11}$. De hecho,

menos, primera década del siglo XIX. A.D.Z., Libros de Acuerdos del hospital de La Encarnación y Libros de Acuerdos del hospital de Sotelo.

7. La voluntad que se recoge en su testamento, a este respecto, es la siguiente: «mucha gente honrada enferman e sus casas y padecen extrema necesidad por no tener con que curarse y siendo los dichos aposentos cerrados se curaran en secreto». A.D.Z. Leg. 65 (1).

8. Las cofradías de enterradores, que surgieron asociadas a una de las grandes preocupaciones de la época: la salvación del alma, podemos encontrarlas en numerosas ciudades y villas y muchas de ellas vinculadas a centros hospitalarios. Vid. López-Guadalupe Muñoz, Miguel Luis y Arias de SaAvedra Alías, Inmaculada: «Cofradías y ciudad en la España del siglo XVIII», Studia Histórica. Historia moderna, 1998, nº 19, pp. 197-228, p. 214. Sabe Andreu, Ana María: Las Cofradías de Ávila en la Edad Moderna, Ávila, 2000, pp. 258-259.

9. A.D.Z., Libros de Acuerdos del hospital de La Encarnación.

10. En Zamora, al igual que en otros hospitales de Castilla la Vieja, los acuerdos entre la Real Hacienda y los centros de sanidad se hacían directamente, sin que mediara intermediario o «asentista». Vid. LópEz GómEZ, José Manuel: «La asistencia sanitaria a militares enfermos en el Burgos del último tercio del siglo XVIII», Boletín de la Institución Fernán González, 1997, n 215, pp. 245-272, pp.247-248.

11. En uno de los alegatos que posteriormente hicieron ante el monarca, manifestaban que, por Real Orden de Felipe V, se habían puesto en el hospital unas camas «para la hospitalidad de los militares desde el asedio del fuerte de Carbajales». La ocupación de éste, por los portugueses, tuvo lugar durante la Guerra de Sucesión, concretamente en 1710. A partir de ese momento el ingreso de militares debió de ser cada vez más frecuente: «se han refugiado en dicha casa hospital los militares enfermos desde principios de la guerra hasta la presente estación, ocupando para su curación las cuadras bajas y otras estancias de él, 
en abril de 1737, el patronato elevó una petición al Rey para que edificara un hospital militar en la ciudad, al igual que había hecho en otras plazas. Apoyaba la solicitud en el testamento del fundador, que sólo contemplaba «atender a los enfermos naturales de dicha provincia y a los transitantes» ${ }^{12}$, y la reforzaban apelando a los inconvenientes que causaban entre los enfermos la curación de los soldados. En julio de 1738 una Real Orden liberaba a la institución de aquellas prestaciones. Por esas mismas fechas, el monarca envió a Zamora una delegación para que arrendara un edificio ${ }^{13}$, con capacidad para ochenta y cuatro camas, que harían las veces de hospital militar.

Pero en septiembre de $1740^{14}$ los responsables del hospital tuvieron conocimiento de que el Rey había ordenado desalojar la casa que servía de hospital militar ${ }^{15} \mathrm{y}$, a pesar de las suplicas para liberarse de la presencia de soldados, ese mismo año ya fallecieron en La Encarnación once. La siguiente información que poseemos sobre este asunto es del mes de enero de 1749, y se refiere a las diversas reuniones que había tenido el patronato con las autoridades locales, civiles y militares, para manifestarles su desacuerdo con unas reales órdenes emitidas el año anterior. En la primera, de 20 de noviembre de 1748, el Intendente de Salamanca y Comisario de Guerra de la plaza de Zamora ordenaba que «las tropas entren y se curen en los hospitales de los pueblos de sus destinos»; y la segunda obligaba directamente a los patronos de los hospitales zamoranos a ofrecer ese servicio. El asunto quedó zanjado con la carta que recibieron del marqués de Ensenada, que leyeron en la junta de enero de 1749: el de La Encarnación quedaba obligado a recibir solados e, incluso, recomendaban a los patronos que agradecieran al monarca que les pagara por las estancias ${ }^{16}$.

incomodando a los pobres enfermos». Los registros de entradas de soldados, incluso para aquellos años que parecen estar completos, no ofrecen gran fiabilidad, pues en los acuerdos del patronato constantemente se hizo referencia a la falta de rigurosidad con la que se elaboraban. No obstante, la media de soldados muertos en el hospital entre 1728 y 1730 fue de 23,6, casi tres veces más que las registradas en la década precedente. A.D.Z. Libros de Acuerdos del hospital de La Encarnación y Libros de defunciones.

12. La estrategia de recurrir a las disposiciones del fundador, para intentar evadirse de prestar auxilio a militares, fue seguida, también infructuosamente, por los patronos de otros hospitales. López GómEz, José Manuel: «La asistencia sanitaria a militares...», p. 251.

13. Concretamente unas casas que pertenecían a unos menores que residían en Burgos, los hijos de D. Diego Vega Portocarrero. En ellas no debía de haber espacio suficiente para cubrir las necesidades sanitarias, pues en abril de 1739 el patronato había firmado con los representantes de la corona un acuerdo para asistir a militares. A.D.Z. Libros de Acuerdos del hospital de La Encarnación.

14. En el Hospital Real de Santiago se comenzó a prestar, de forma sistemática, asistencia a los militares enfermos a partir del 1 de enero de 1740. Vid. Martínez Rodriguez, Enrique: «Los enfermos del Hospital Real de Santiago: serie completa hasta mediados del siglo XIX (1)», Obradoiro de Historia Moderna, 2000, $\mathrm{n}^{\circ}$ 9, pp. 43-78, p. 58.

15. Según señala Montserrat, el 16 de diciembre de 1741 se suprimieron los hospitales de Zamora, Puebla de Sanabria y Ciudad Rodrigo. En el caso de Zamora ese cierre sería consecuencia, además de las decisiones políticas, de la falta de una infraestructura adecuada. Vid. MonTSERrat Figueras, Sebastián: La medicina militar a través de los siglos, T. II, Madrid, 1946, p. 295; MAssons, José María: Historia de la sanidad militar española, Barcelona, 1994, p. 218.

16. En el informe de hospitales elaborado en 1773, se señalaba que en Castilla la Vieja no había ningún hospital militar, que los soldados eran asistidos en los centros civiles; y en el de 1792 en la ciudad de Zamora 
El cumplimiento de ese mandato real supuso para el hospital de La Encarnación, como también para el de Sotelo, toda una serie de novedades que poco a poco tuvieron que ir afrontando. Como ambos centros eran mixtos y tenían una capacidad muy limitada, una de las primeras medidas que se tomó fue la de reorganizar la labor asistencial, para que los soldados «como las mujeres estuvieran con más comodidad y decencia». Acordaron que se atenderían a los «paisanos» en el fundado por D. Pedro Morán y a las mujeres en el del comendador, a la vez que en ambos ingresarían soldados.

En el hospital de La Encarnación a partir de 1749, según exponían los patronos cuatro años después, funcionaban cuatro salas, o enfermerías: tres para la curación de militares y una para la de paisanos. Eso suponía, atendiendo a las Respuestas Generales del Catastro de Ensenada, ofertar 80 camas al primer colectivo y 26 al otro. Pero la capacidad de las instalaciones no era suficiente para poder cumplir con las nuevas labores de hospital militar, por lo que tuvieron que realizar importantes obras de ampliación y adecuación, que se desarrollaron, con diferente intensidad, a lo largo de toda la centuria ${ }^{17}$. Gran parte de esos trabajos se llevaron a cabo tras firmar, el 23 de febrero de 1761, un contrato con la corona, por el que los patronos del establecimiento se comprometían a acoger hasta $400^{18}$ enfermos militares. Para poder costearlas recibieron un adelanto de la real hacienda de 100.000 reales, que iban a amortizar mensualmente, dejando de cobrar en cada uno de ellos un tercio de las estancias. Debía de ser muy importante el negocio que esperaban hacer, pues asumían un gran riesgo, debido a que sólo podían liquidar el anticipo con la recaudación procedente de la demanda asistencial de los militares, cuyo volumen estaba en función del número de soldados enviados a la plaza y del tiempo que estuvieran destinados en ella. Para minimizarlo, lograron firmar un convenio por el cual quedaban dispensados de pagar la deuda pendiente en caso de que el ejército solamente hiciera uso de sus instalaciones un año.

La llegada de militares no sólo supuso una mayor demanda asistencial, también la necesidad de adecuar las prestaciones, por ejemplo, entre los soldados eran frecuentes enfermedades contagiosas que hasta entonces no se curaban en el hospital. Los patronos, amparándose en la voluntad del fundador, solicitaron al monarca que les autorizara a prohibir la entrada de aquellos que padecieran «mal gálico, sarnosos, tísicos y otros». No tenemos constancia de que esa suplica fuera atendida, pues, al menos,

desempeñaba esa actividad el de La Encarnación. Massons, José María: Historia de la sanidad... pp. 224-225.

17. La ampliación de hospitales, o incluso reedificación, para dar cabida a militares se repite en otras ciudades, caso de Pamplona o Burgos. Ramos Martínez, Jesús: La salud pública y el Hospital General de la Ciudad de Pamplona en el Antiguo Régimen (1700 a 1815), Pamplona, 1989, p. 368. SANZ DE LA Higuera, Francisco José: «Remodelaciones en el Hospital de Barrantes (1767-1800). Cabildo, cirujanos, pobres, soldados, quadras y camas», Brocar, 2009, n 33, pp. 67-114.

18. En los registros de La Encarnación no ha quedado constancia de los ingresos de soldados durante la década de los cincuenta, pero, a través de los libros de Acuerdos, conocemos algunos datos, como, por ejemplo, que en 1759 había «bastantes soldados milicianos enfermos en este hospital», o que unos meses antes el médico solicitó un aumento de salario por las unciones que había practicado. A.D.Z. Libros de Acuerdos del hospital de La Encarnación. 
desde los años finales de la década de los cincuenta del siglo XVIII, la práctica de unciones $^{19}$, por parte del personal sanitario de La Encarnación, fue muy frecuente. Así mismo, también hubo necesidad de ampliar la plantilla del centro, que hasta entonces se había mantenido, prácticamente, tal y como había dispuesto D. Pedro Morán en su testamento ${ }^{20}$. A partir de entonces, el número de personas que pasaron a trabajar en el hospital, así como su salario, sufrieron constantes variaciones, derivadas del volumen de enfermos que en cada momento debían atender ${ }^{21}$.

Respecto a las ventajas que supuso para La Encarnación el realizar labores de hospital militar, esas, indudablemente, fueron de carácter económico. En la primera contrata se fijó el precio de las estancias de los soldados en cinco reales al día. Incluía asistencia médica y, por supuesto, espiritual, la medicación que necesitaran y alimentación de «primera calidad». Posteriormente ese importe se rebajó, por lo que en los últimos años del siglo XVIII, cuando encareció considerablemente el precio de los productos alimenticios, los patronos se plantearon solicitar al monarca que les eximiera de la prestación de ese servicio. No llegaron a iniciar el proceso, porque, si en ese momento se las subieron en medio real por día ${ }^{22}$, poco después, a raíz de las crisis de 1801 , lograron cobrarlas a seis. Pero al margen de esas fluctuaciones y de las tensiones que por ese motivo surgieron, es indudable que el acuerdo con la corona les proporcionó importantes ingresos. Por ejemplo, según declaraban en 1752, la ganancia media anual en ese momento, con dos batallones en la ciudad, ascendía a 113.000 reales, lo que suponía quintuplicar las rentas del centro, que en ese momento situaban en $22.000^{23}$.

19. Sobre este tratamiento para curar la sífilis, Vid. VAlenzuela CANDElario, José: El hospital Real de Granada y sus constituciones de gobierno, Granada, 2008, pp.23-25

20. Los militares eran atendidos por el mismo personal sanitario y de servicios que el resto de los enfermos, salvo en algún momento puntual, como fue en 1762, en que desconocemos la razón por la que tuvieron sus propios médicos. A.D.Z. Libros de Acuerdos del hospital de La Encarnación.

21. En 1752 hubo una importante actualización de los salarios: el de los médicos pasó de 500 reales al año a 2.700 , el del cirujano de 300 a 1.500, al administrador y despensero les aumentaron 2 reales al día, de 4 a 6, y además al primero le pusieron un ayudante. El valor de los salarios, estaba en función de la presencia de tropas en la ciudad, así, por ejemplo, en 1762 a los médicos les duplicaron el sueldo anual, que pasó de 1.800 reales a 3.600, la mitad para cada uno. En enero de 1765 subían el de los practicantes y enfermeros -por «el más trabajo de la tropa»-, mientras que tres meses después se lo reducían - «en atención a los pocos enfermos militares»-- A.D.Z. Libros de Acuerdos del hospital de La Encarnación. La retribución de los médicos era elevada, si la comparamos con la que recibían los que trabajaban en el Hospital de Gracia, aunque a éstos no se les computa la manutención y el alojamiento. En Pamplona, para compensarlos por el aumento de trabajo que originaba la presencia de militares, se acordó pagarles una cantidad adicional por cada una de aquellas estancias. Fernandez Doctor, Asunción: El hospital Real y General de Nuestra Señora de Gracia de Zaragoza en el siglo XVIII, Zaragoza, 2000, pp. 106108; Ramos Martínez, Jesús: La salud pública y el Hospital General... p. 282.

22. En septiembre de 1797 acordaron con los representantes de la corona que la estancia de soldado con graduación menor a la de sargento la pagarían 4,5 reales y la de los oficiales a 5 .

23. Sólo esa asistencia y la buena gestión del patrimonio del centro podía permitir a la fundación alguna ganancia, pues la actividad ordinaria, atender a los necesitados, sólo podía generar déficit. RoJo VEGA, Anastasio: «Enfermedades hospitalarias en la España interior del siglo XVII», Medicina e Historia, $2000, n^{\circ} 1$, pp. 1-15. 


\section{LA ORGANIZACIÓN HOSPITALARIA}

Hasta 1760, en que se redactaron unas nuevas ordenanzas, el hospital de La Encarnación se gobernó por las normas que había establecido su fundador ${ }^{24}$. La necesidad de esos nuevos estatutos surgió del aumento de actividad y de trabajadores que experimentó el centro tras los acuerdos con la corona. De acuerdo con el nuevo reglamento, el órgano máximo de gobierno continuaba siendo el patronato, formado por cuatro personas, de las que sólo tres asistían con regularidad -el representante del regimiento, el del cabildo y el prior de San Jerónimo-. Entre sus obligaciones estaban el aplicar medidas disciplinarias, inspeccionar y autorizar gran parte de la actividad económica ${ }^{25}$, ayudados por el administrador y el mayordomo, o la contratación de personal.

La administración recaía en el mayordomo y un administrador eclesiástico, ayudados por un secretario. La misión del primero era velar por la conservación del patrimonio y la gestión del mismo. Por su parte, el administrador era la persona con mayor responsabilidad en el hospital ${ }^{26}$. Este cargo ya había sido establecido por el fundador, que le había encomendado el control de la actividad diaria del establecimiento y de sus trabajadores, así como la atención espiritual de los asistidos. Entre los cometidos que les asignaban los estatutos de 1760 estaban el inspeccionar las despensas, asegurándose que estuvieran limpias y abastecidas, autorizar diariamente el suministro de víveres e incluso estar presente en el momento de servir las comidas y cenas, para comprobar que los internos recibían la cantidad adecuada de alimento y las medicinas que les habían mandado los facultativos. También era obligación suya comprobar la limpieza de las instalaciones, revisar el ropero, inspeccionar los libros de ingresos de enfermos, intervenir en la autorización de gastos, junto con el mayordomo, o colaborar con aquel en el control de las estancias militares que se debían facturar a la intendencia del ejército.

La platilla sanitaria la formaban los médicos, el cirujano, los practicantes y los enfermeros. El patronato de La Encarnación, al menos desde la década de los cincuenta del siglo XVIII, tenía contratados dos médicos, para atender este centro y el de Sotelo, que trabajaban por turnos de un mes y se repartían el salario anual que tenía asignada la plaza. Esos relevos les permitían compatibilizar el trabajo en los hospitales con la actividad privada, pero dado que ésta les debía de resultar más rentable, porque en aquellos momentos en que los centros les exigían más dedicación lo abandonaban, acabaron

24. A.D.Z. Leg. 70 (3).

25. En este campo se ha de incluir todo lo relativo a los ingresos y gastos del centro, desde la administración del patrimonio hasta fijar los salarios y las primas o establecer el número de arrobas de carbón que diariamente debía entregar el despensero al cocinero y a los enfermeros.

26. Uno de los administradores que más tiempo permaneció en el hospital fue D. Manuel Flórez. A lo largo de los treintaicuatro años que desempeñó el cargo (1762-1796), tal y como expone en su memorial de despedida, tomó medidas que no fueron del agrado de todos los empleados. Llego a anticipar al centro algo más de 14.800 reales, que en su retiró cedió para los pobres. A.D.Z. Libros de Acuerdos del hospital de La Encarnación. 
por contratarlos con dedicación exclusiva ${ }^{27}$. Médico y cirujano debían de hacer dos visitas diarias a los enfermos, una por la mañana y otra por la tarde, y acudir cuando se presentara cualquier urgencia. Hubo momentos en que las relaciones entre ambos facultativos fueron especialmente difíciles, debido a lo que consideraban intromisiones profesionales. Estas intentaron zanjarse, sin ningún éxito, con el reglamento de 1760, que les exigía colaboración en el trabajo, ya fuera a la hora de administrar las unciones o de realizar las visitas a los pacientes ${ }^{28}$.

Los practicantes, cuyo número variaba en función de las salas que estuvieran abiertas, debían acreditar ante el patronato que gozaban de la debida preparación y, una vez superado ese primer filtro, tenían que aprobar un examen que les hacían los médicos o el cirujano, dependiendo de la plaza a la que aspiraran. Entre sus actividades estaban el informar a los superiores de la evolución del paciente, porque eran los que tenían contacto más directo con ellos, practicar sangrías y curas, aplicar ventosas o acompañar a sus superiores en las visitas, anotando en los libros, que cada mañana recibían del administrador, el tipo de alimentación que debía recibir cada enfermo. A continuación, y con el visto bueno del administrador, debían entregar al despensero un resumen de las raciones que se iban a necesitar en la comida y en la cena ${ }^{29}$. A partir de 1778 se exigió a los que aspiraban a desempeñar esta actividad que fueran solteros y se limitaron los contratados a cinco años. Ese era el tiempo que consideraban necesario para que un practicante se habilitara y pudiera ingresar en la facultad correspondiente; además, de esta forma, esperaban ofrecer un servicio a la comunidad, pues podrían pasar por esta escuela un mayor el número de interesados.

Por debajo de los practicantes estaban los enfermeros, que eran los encargados del aseo de las salas y de los enfermos. En este caso, ya desde 1734, los candidatos a ejercer el oficio debían estar solteros, «pues no era decente que durmiera con su mujer

27. En octubre de 1765 se despidió uno de los médicos, D. Felipe Pardo, porque tenía muchos enfermos particulares y no podía atender el centro; poco después lo hizo el otro, D. Manuel, por el mismo motivo. El patronato acordó contratar a D. José Vicente, médico en Toro, «para que por sí solo asista paysanos y militares», con un salario de 300 ducados al año. No tardó en renunciar a la plaza, para trasladarse a León. No obstante, en 1771, en el contrato firmado con D. Blas Antonio Hermosa, al que pagarían 4.000 reales al año, se volvía a contemplar la posibilidad de que pudiera atender a particulares. A.D.Z. Libros de Acuerdos del hospital de La Encarnación.

28. En 1761 surgieron problemas entre el médico y el cirujano porque, según el primero, el otro se entrometía en su campo. El patronato le ordenó que «no haga más curas que aquellas que por su facultad de tal cirujano ejerce y le están permitidas, sin embarazar al médico». En junio de 1766 el motivo era a quién le correspondía curar la sarna y en octubre por las unciones, que acordaron fueran competencia del cirujano. En febrero de 1780 el médico, D. Juan Bautista Rizzi, elevaba una queja al patronato por la forma en que unos meses antes el cirujano, D. José de Colino, le había tratado en presencia del ayudante de botica, los enfermeros y otro personal. A raíz de este episodio decidieron jubilar al cirujano, con una paga vitalicia de dos reales al día y la condición de asistir al hospital cuando hubiera alguna urgencia. A.D.Z. Libros de Acuerdos del hospital de La Encarnación.

29. A las visitas también asistía el mancebo de la botica, para garantizar que no se produjeran errores en la administración de los medicamentos. Práctica habitual en otros hospitales. Fernandez Doctor, Asunción: El hospital Real y General...p. 214. 
en la enfermería». Entre las órdenes dadas en 1800, por el intendente a los responsables del hospital, estaba la de que hubiera un enfermero por cada 20 pacientes.

En el reglamento regularon las competencias del boticario y su mancebo. En 1753 los patronos habían acordado comprar una botica para el centro, pues hacia años que estaban prestando servicios a la corona y las ganancias que habían obtenido les permitían realizar esa inversión, pero aún tardaría tres años en concretarse la adquisición ${ }^{30}$. Hasta aquella fecha habían surtido al hospital algunas boticas particulares y en 1744 se acordó que fuera la de los Jesuitas. No obstante, el proveedor que durante más tiempo abasteció a La Encarnación fue el convento de San Jerónimo, del que con cierta frecuencia se planteaban prescindir, por la lejanía del centro y las dificultades para el abasto inmediato, sobre todo por la noche cuando cerraban las puertas de la ciudad. Pero esa medida no se hizo efectiva, no olvidemos que el prior de ese convento formaba parte del patronato.

La botica también abastecía al hospital de Sotelo, surtía gratuitamente a los empleados y despachaba al público. A partir de la década de los setenta este negocio dejó de ser rentable, debido a que el difícil contexto económico que sufría la población dificultaba los $\operatorname{cobros}^{31}$. Para corregir esa situación decidieron, en 1783, elaborar un reglamento que regulara la actividad de la farmacia, en el que se recogía la prohibición de realizar ventas al fiado, pero no tuvo la efectividad que esperaban ${ }^{32}$.

Para la asistencia religiosa, desde que el administrador eclesiástico fue relevado de la misma, contrataron a un capellán: el «agonizante». Debía vivir en el hospital, para poder suministrar con diligencia los sacramentos, a civiles y militares, y vigilar de cerca la conducta moral de los trabajadores ${ }^{33}$.

Otro grupo de trabajadores lo formaba el personal de servicios, en el reglamento 1760 recogieron, entre otros: despensero, comprador, guardarropa o cocinero. Pero, además, estaban las lavanderas, costureras o criados. El número de todos ellos oscilaba en función de la actividad que tuviera el hospital ${ }^{34}$.

30. En 1756 el comisario retomó la cuestión, proponiéndoles la adquisición de una que acababa de quedar vacante. Les pedían 4.600 reales, que decidieron negociar, «por los pertrechos y diferentes remedios y frascos de vidrio de la botica». A.D.Z. Libros de Acuerdos del Hospital de la Encarnación.

31. En 1779 el alguacil mayor logró cobrar 1.400 reales «de recetas atrasadas que debían varias personas a la botica y aún restaban por cobrar otras muchas que ejecutarían con despacho de la justicia real». A.D.Z. Libros de Acuerdos del hospital de La Encarnación.

32. En 1786 Antonia de la Peña pedía al patronato que le perdonaran el gasto al fiado que había hecho en la botica durante la enfermedad de su esposo, en atención a que éste había dejado en herencia al hospital una casa y una bodega. Los problemas con la botica siguieron en la década de los noventa, incluso llegaron a cerrarla durante un tiempo. A.D.Z. Libros de Acuerdos del hospital de La Encarnación.

33. El alivio espiritual de los enfermos ocasionó algunos problemas al patronato, debido a cuestiones competenciales y fundaciones mal atendidas. Por ejemplo, en 1759, hubo un pleito entre las parroquias de San Juan, San María y San Carpiano, por la jurisdicción y el derecho parroquial de la iglesia del hospital. A.D.Z. Libros de Acuerdos del hospital de La Encarnación.

34. Cuando se refirieron a ellos lo solían hacer en plural, nunca dando un número. Por ejemplo, el caso de las criadas, en diciembre de 1679 acordaron subirles el salario a 1.000 maravedís, al considerar que 
Con tanto personal era inevitable que surgieran problemas, de ahí que fueran frecuentes las amonestaciones, e incluso hubo algunos despidos ${ }^{35}$, fundamentalmente de practicantes y enfermeros que abandonaron el centro durante la noche o no trataron a los enfermos con la «caridad y celo correspondiente». También fue echado algún cocinero, por «la poca limpieza que usa» y no hacer aprecio de las amonestaciones.

El procedimiento para el ingreso de los enfermos lo había dejado establecido el fundador y, con ligeros cambios, así se mantuvo en el siglo XVIII. A cualquier hora del día se podía solicitar la admisión en el hospital. Los médicos y el miembro del patronato que estuviera de guardia, o en su defecto el administrador, eran los encargados de evaluarla y autorizarla, respectivamente. El siguiente paso era la entrevista con el capellán, que, tras confesar y dar de comulgar al enfermo, otorgaba el certificado definitivo. En 1767 se eximió a los pacientes graves de ese último trámite, al considerar que la dolencia les impediría hacer una buena confesión, requisito indispensable para la limpieza y salvación del alma. Una vez formalizado el ingreso, el paciente debía entregar su vestimenta al guardarropa, que se encargaba de higienizarla y custodiarla hasta que recibiera el alta.

A pesar de que D. Pedro Morán decretó que se respetaran una serie de disposiciones orientadas a mantener la higiene en el centro, parece que las salas acabaron por convertirse en un espacio muy poco salubre, o al menos eso es lo que se desprende de las recomendaciones hechas en 1763 por dos médicos enviados por el Rey para inspeccionar los hospitales de Zamora. Casi todos los hábitos que recomendaban adquirir, y que ayudarían a los pacientes a recuperar la salud ${ }^{36}$, estaban relacionados con el aseo y la necesidad de purificar el ambiente. Ordenaban que hicieran sahumerios con frecuencia, que pusieran en todas las salas juncieras, se abrieran las ventanas cuatro veces al día, por espacio de cuatro minutos, para ventilar, que utilizaran jofainas para que los enfermos no escupieran en el suelo o que los recipientes usados para defecar se taparan con un lienzo y se colocara una madera encima. Parece que esos mandatos no se respetaron con la debida diligencia, pues en 1778 los patronos requerían a sus empleados el cumplimiento de los mismos. Unos años después, en 1800, el intendente completaba aquella lista de recomendaciones proponiendo que se hiciera una linterna en el techo de las salas para mejorar la ventilación o que se mudaran las sábanas cada quince días.

era demasiado bajo para la carga de trabajo que desempeñaban. En 1682 sólo tenían un criado varón, y acordaron que para vestirlo utilizarían los 100 reales en que estaba arrendada la venta de las ropas de los pobres. En la misma fecha, contrataron a su esposa, también criada en el centro, como costurera, pagándole 1,5 reales al día. A.D.Z. Libros de Acuerdos del hospital de La Encarnación.

35. Como el del practicante Galindo, en febrero de 1761, por dormir fuera del hospital «una de las noches de carnestolendas». A.D.Z. Libros de Acuerdos del hospital de La Encarnación.

36. La falta de limpieza afectaba también a las estancias de los trabajadores del centro. En 1776, los miembros del patronato se quejaban de que la sala de reuniones, que era donde residía el auxiliar del clérigo, estaba tan indecente y con tan malos olores que era preciso trasladarse. A.D.Z. Libros de Acuerdos del hospital de La Encarnación. 


\section{LA DINÁMICA ASISTENCIAL}

Conocer la evolución de la demanda asistencial en la Edad Moderna en un centro hospitalario de estas característica, nos remite a la dinámica de la pobreza, si bien esa estuvo tan arraigada en aquellas sociedades que constituía un rasgo estructural de las mismas. Para poder reconstruir la actividad desarrollada en el de La Encarnación disponemos de datos, de diferente naturaleza, desde enero de 1678 hasta julio de 1788 . Durante los dos primeros años anotaron el nombre de paciente y su procedencia, la fecha de ingreso y, en caso de fallecimiento, la del óbito; entre julio de 1680 y agosto de 1767 solamente registraron a los enfermos que fallecieron y desde entonces hasta 1788 vuelven al esquema inicial. Según los datos aportados por esos registros, fallecieron en La Encarnación 2.644 personas desde 1678 hasta $1767^{37}$ y entre 1768 y 1787 ingresaron 8.582 varones. En lo que respecta a los militares, los datos de las estancias que hemos localizado son muy incompletos. Reiterar que este centro ofreció asistencia a hombre y a mujeres hasta los años cuarenta del siglo XVIII, en que, a raíz de los acuerdos firmados con la corona, aquellas fueron trasladadas al hospital de Sotelo

A lo largo del siglo XVIII, y de forma global, el 54\% de las personas fallecidas o que ingresaron el hospital de La Encarnación era de la provincia de Zamora ${ }^{38}$, repartiéndose casi a partes iguales entre la ciudad y el entorno rural. Del 46\% restante, el colectivo con mayor importancia fue el de los gallegos, fundamentalmente orensanos, con una demanda estacional muy clara. Entre 1695 y 1719 las gentes del Reino de Galicia representaron más del $30 \%$ de los fallecidos en La Encarnación y desde esa fecha hasta 1743 superaron el 40\% $\%^{39}$. Les siguieron los castellanoleoneses, cuya presencia osciló entre el 13,3\% y el 7,3\%. El resto de los fallecidos e ingresados procedían de Portugal, Asturias, Andalucía, Extremadura, Madrid e incluso Cataluña o algún país extranjero.

Una de las primeras cuestiones que nos hemos planteamos a la hora de analizar la coyuntura asistencial de La Encarnación es, si para esa etapa en la que no disponemos de un registro de ingresos podemos reconstruir los ciclos de demanda partiendo de las

37. Hemos prescindido de los datos del segundo quinquenio de la década de los cuarenta del siglo XVIIII, porque están muy incompletos.

38. Lo que nos ofrece un radio de acción benéfica superior al del hospital de San Antolín de Palencia o el de San Juan de Astorga. En el primero el 72,9\% y en el otro el $80 \%-90 \%$ entre las mujeres- de los atendidos eran de la provincia. Marcos Martín, Alberto: Economía, sociedad y pobreza en Castilla. Palencia, 1500-1814, Palencia, 1985; MarTín GARcíA, Alfredo: «Pobres y enfermos en el León de la Edad Moderna: la asistencia hospitalaria en la ciudad de Astorga», en Laureano M. RuBIo PÉrez (coor.), Pobreza, marginación y asistencia en la Península Ibérica (siglos XVI-XIX), León, 2009, pp. 65-97.

39. La presencia del colectivo gallego en el hospital zamorano de la Encarnación fue mucho más importante, tanto en términos absolutos como relativos, que en el de San Antonio de León, donde, entre los forasteros, cabe destacar a los asturianos. En cambio, sí que fue más frecuente su presencia en el de San Juan de Astorga, pues esta ciudad les era más favorable en su ruta de desplazamiento. MARTín García, Alfredo: «Pobres y enfermos en el León...65-97; PÉrez Álvarez, M. José: «Enfermedad y caridad en la provincia de León durante la Edad Moderna: El Hospital de las cinco Llagas de la ciudad de Astorga», 2011, Hispania Sacra, 2011, no 63, pp. 75-102. 
defunciones. Hemos de tener en cuenta que la relación entre ingresos y fallecimientos no es proporcional, debido a que la incidencia puntual de determinadas enfermedades podía disparar las tasas mortandad. Situaciones de ese tipo las hemos podido constatar en algunos momentos de la segunda mitad del siglo XVIII, cuando poseemos el doble registro, ingresos y óbitos. Por ejemplo, en 1778 fallecieron 83 personas, de las 604 que ingresaron, una más que en 1770 , cuando el centro recibió prácticamente la mitad de enfermos. Ese tipo de fluctuaciones, como es bien sabido, tienden a equilibrarse cuando manejamos periodos temporales más amplios. De hecho, en este hospital, la oscilación anual de la mortandad, que se movía entre el 9,9\% y el 26,8\%, quedó reducida a dos puntos, entre el $15 \%$ y poco más del 17\%, en el momento en que redujimos los cálculos a quinquenios (cuadro $\left.\mathrm{n}^{0} 1\right)^{40}$. Así pues, una vez neutralizadas esas fluctuaciones, el recorrido que describe la mortandad nos aproxima a la evolución de la demanda asistencial.

\section{Cuadro $n^{0}$ 1. Porcentaje de fallecidos, respecto a los ingresados en el hospital de La Encarnación entre 1768 y 1787}

\begin{tabular}{|c|c|c|c|}
\hline & Ingresos & Fallecidos & \% \\
\hline $1768-1769$ & 674 & 105 & 15,6 \\
\hline $1770-1774$ & 2299 & 344 & 15,0 \\
\hline $1775-1779$ & 2509 & 378 & 15,1 \\
\hline $1780-1784$ & 2072 & 318 & 15,3 \\
\hline $1785-1787$ & 1028 & 176 & 17,1 \\
\hline
\end{tabular}

La serie de datos que hemos reunido, a partir de los registros de defunciones, nos refleja dos etapas claremente diferenciadas en el hospital de La Encarnación. La primera iría desde la apertura del centro hasta la década de los sesenta del siglo XVIII, en la que se inicia la otra. La mayor actividad que refleja el centro durante la segunda etapa fue el resultado de la ampliación de las instalaciones, tras los contratos firmados con la Corona para acoger militares (gráfico $n^{\circ} 1$ ).

En cada una de esas dos fases, en las que se divide la trayectoria evolutiva de la mortandad en el hospital zamorano, se pueden apreciar ciclos que se apartan de la tendencia. En la primera hubo dos momentos especialmente nefastos, prácticamente encadenados y de diferente intensidad ${ }^{41}$. El primero, y más catastrófico, tuvo lugar en

40. Es algo más elevada que en el hospital de Gracia de Zaragoza, donde, casi un siglo antes, se situó en el 14,2\%. Fernandez Doctor, Asunción: El hospital Real y General... p. 204.

41. Las circunstancias en las que recogieron a dos varones y una niña, de entre once y trece años, puede servirnos como ejemplo de las dificultades que se vivían esos años. Estos muchachos «estaban encima de los poyos del portal y por su necesidad los recogimos dentro, no supimos nada de ellos»; la niña «estaba en el poyos de atrás». Los tres fallecieron el día del ingreso. 
el último quinquenio del siglo XVII, en el que fue especialmente mortífero el bienio 1698-99, cuando la cifra anual de muertos -50,1- aumentó considerablemente respecto a la media de la etapa -en torno a 20 fallecidos-. El otro, que en sus comienzos sería una prolongación de la crisis finisecular del siglo XVII, aunque menos dramático, se extendió hasta el final de la Guerra de Sucesión. A lo largo de esos, aproximadamente, tres quinquenios la cifra media de defunciones fue unas 25,5 por año. En el aumento de la actividad hospitalaria, que se constata en ambas etapas, fue de vital importancia la llegada de forasteros. De hecho, más de dos tercios de los funerales acontecidos entre 1695 y 1699 o entre 1710-14 fueron gentes llegadas de fuera de la provincia, las cuales alcanzaron el 84,3\% en el quinquenio 1705-1709 (gráfico $\mathrm{n}^{\circ} 2$ ). Entre esos foráneos cabe destacar a los gallegos, cuya presencia en el centro zamorano creció en un $70 \%$ en la última década del siglo XVII y primera del XVIII ${ }^{42}$, a raíz de las desfavorables coyunturas agrarias sufridas. Con el final del conflicto bélico se produjo un retroceso de la mortandad, debido a la menor presión ejercida parte de los forasteros y al periodo de relativa tranquilidad y recuperación que comenzó a vivirse en la provincia de Zamora $^{43}$.

\section{Grafico $n^{0}$ 1. Defunciones en el hospital de la Encarnación (1678-1787)}

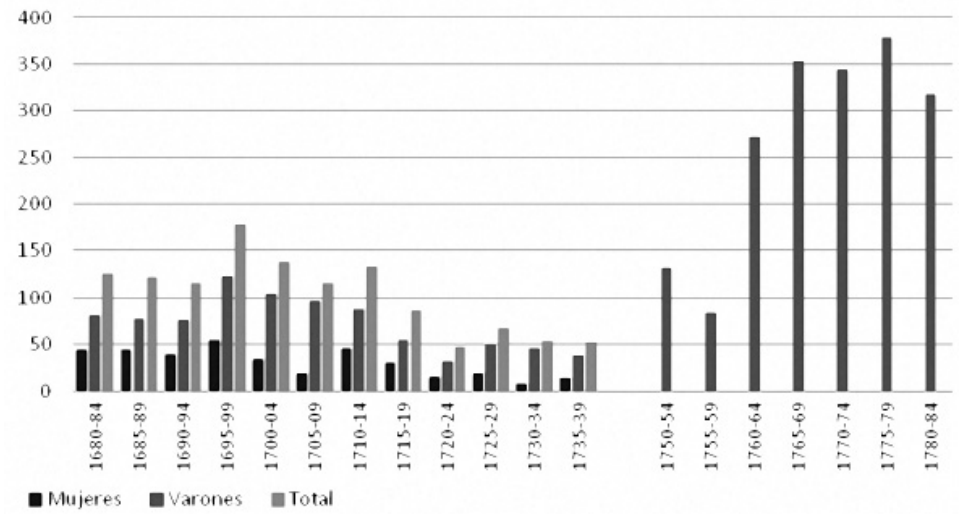

42. Respecto a las cronologías de las mismas, Vid. Eiras Roel, Antonio: «Producción y precios agrícolas en la Galicia Atlántica en los siglos XVII-XVIII. Un intento de aproximación a la coyuntura agraria», Congreso de Historia Rural. Siglos XV al XIX, Madrid, 1984, pp. 393-413, p. 406.

43. Alvarez Vázquez, José Antonio: «La agricultura de Zamora en la época moderna», Historia de Zamora, Edad Moderna, T. II., Zamora, 1995, pp. 113-145, p. 137. 


\section{Gráfico $n^{0}$ 2. Procedencia de los difuntos e ingresados en el Hospital de La Encarnación (1680-1781)}

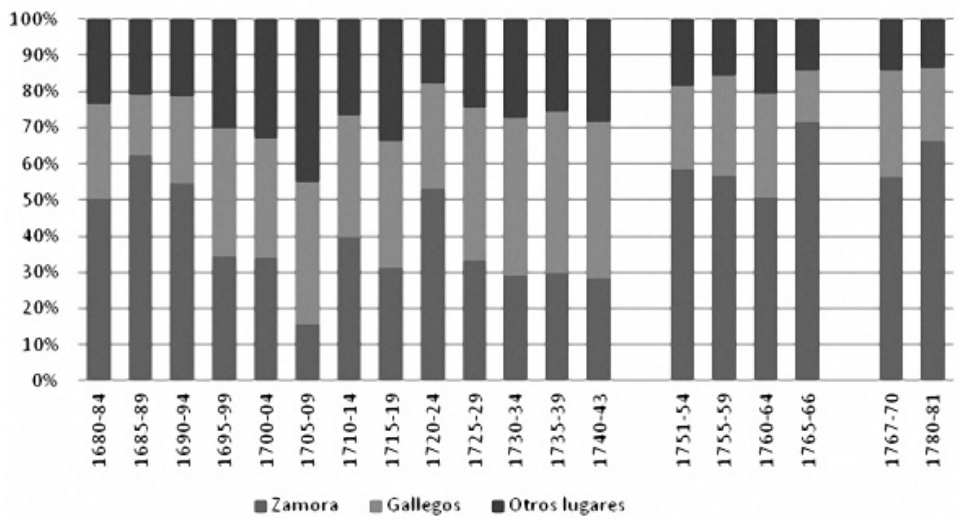

El segundo periodo, que se inició en la década de los sesenta, se caracterizó por una actividad mucho más intensa, como resultado de la edificación de nuevas estancias y la consecuente mayor capacidad de acogida. Entre 1760 y 1787 la media anual de fallecidos llegó a ser tres veces superior a la que se alcanzó en la primera mitad de la centuria. En esas cifras quedó reflejada la coyuntura agrícola que padeció la provincia zamorana, que había comenzado a manifestarse en la década de los cuarenta del siglo XVIII ${ }^{44}$. Estuvo marcada por la subida del precio del cereal, tras el aumento de la renta y el descenso de la producción.

Por otro lado, cabe destacar que a partir de 1750, tal y como se comprueba en la muestra que hemos sacado de la procedencia geográfica de los difuntos, la presencia de zamoranos en el centro no bajó en ningún momento del 50\%, llegando a suponer el $70 \%$ entre 1765 y 1766 . A su vez, el aumento que experimentó la demanda de asistencia de las gentes que vivían en la capital, nos refleja el proceso inmigratorio que vivió en la segunda mitad de la centuria dieciochesca. Surgió aquel de las crisis económicas sufridas en los años sesenta, que empujaron a los arrabales de la ciudad a los campesinos pobres y jornaleros. Los efectivos demográficos de la ciudad de Zamora crecieron un $16,6 \%$ desde 1752 hasta 1768 , prácticamente lo mismo que entre ese último año y 1787. Por su parte, para esas mismas fechas, las defunciones hospitalarias subieron en un $31,7 \%$ y $72,5 \%$, respectivamente, lo que evidencia el proceso de pauperización que se vivía.

44. Alvarez VÁzQuez, José Antonio: «Evolución de los arrendamientos agrícolas de 1450 a 1850 en Zamora», Congreso de Historia Rural. Siglos XV al XIX, Madrid, 1984, pp. 613-623, pp.620-621; «La agricultura de Zamora..., pp. 113-145. Rueda, José Carlos, Fernández Juan Francisco y Velasco Eduardo: «La población zamorana, siglos XVI-XIX», Historia de Zamora, Edad Moderna, T. II., Zamora, 1995, pp. 249-341, p. 293. 
El ciclo más mortífero de esta etapa tuvo lugar en el bienio 1765-1766, en el que culminó una tendencia nefasta que se había iniciado a comienzos de la década ${ }^{45}$. Había sido provocada por una sucesión de pésimas $\operatorname{cosechas}^{46}$, que, en el conjunto de la Corona de Castilla, se padecieron entre 1762 y $1765^{47}$. El incremento de las defunciones, respecto a la década precedente, fue de un 168\% entre los zamoranos, poco más del 150\% para los gallegos y ligeramente más bajo en el resto de las procedencias, el $130 \%$. Los Libros de Acuerdos del hospital dejaron abundantes noticias sobre las consecuencias que tuvo para la centro la falta de cereal. En otras, encontramos que en abril de 1763 gratificaron al panadero por desplazarse «cuatro leguas a comprar harina por no tenerla la ciudad»; o que, al año siguiente, los empleados pidieron una subida de salario, pues debido a la carestía el sueldo no les alcanzaba para vivir.

Muy complicada fue también para La Encarnación la década de los setenta, en general, durante la cual se llegó a alcanzar una media de 72,2 defunciones al año. Como a partir de 1767 se llevó a cabo el registro de ingresos, podemos conocer con más detalle la actividad asistencial del centro durante las dos últimas décadas para las que poseemos datos (gráfico $\mathrm{n}^{\mathrm{o}} 3$ ). Pues bien, la entrada de enfermos en este hospital durante los setenta se disparó respecto a la media, que se situaba próxima a las 400 , llegándose a colocarse en torno a las 600 entre 1776 y 1778. No obstante, el centro ya hacía años que sufría la presión que generaba ese aumento de la actividad. En 1774 los patronos se quejaban de que la limosna que les había dado el regimiento - que en realidad era la devolución de parte de los impuestos que les cobraba por el consumo de vino, carne y aceite- solamente era algo más elevada que la de años precedentes, a pesar de que en 1773 habían aumentado notablemente el volumen de compras, por el gran número de enfermos civiles que atendieron; en 1775, debido al descenso de las rentas y de los ingresos de militares, plantearon disminuir el número de camas y de trabajadores, y de esta forma aliviar la presión que sufría la economía del centro. Si realmente llegaron a tomar esa medida fue por muy poco tiempo, pues si en 1776 el número de ingresos era más bajo al año siguiente volvían a dispararse.

45. La elevada mortandad hospitalaria es reflejo de la que estaba sufriendo la ciudad, de especial intensidad fue la registrada entre 1762 y 1765 . Rueda, José Carlos, Fernández Juan Francisco y Velasco Eduardo: «La población zamorana...p. 294.

46. Sobre los ciclos de cosechas en la provincia de Zamora, vid. AlvarEz VÁzQuEZ, José Antonio: Rentas, precios y crédito en Zamora en el Antiguo Régimen, Zamora, 1987, p. 154-56.

47. Muy importante fue durante esa década la llegada de gallegos, que se intensificó entre 1768 y 1770 , cuando el territorio sufría una crisis importante. Concretamente, en esos tres años se duplicó la media de gallegos fallecidos en este hospital, respecto a la del trienio precedente. MeIJIDE PARDo, Antonio: «El hambre de 1768-1769 en Galicia y la obra asistencial del estamento eclesiástico compostelano», Compostelanum, 1965, 2, pp. 213-256; EIRAs RoEL, Antonio: La población de Galicia 1700-1860, Santiago, 1996, p. 89. Eiras Roel, Antonio: «Producción y precios agrícolas en la Galicia Atlántica en los siglos XVII-XVIII...», p. 409. 


\section{Gráfico $n^{0} 3$. Varones ingresados y fallecidos en el hospital de la Encarnación (1768-1787)}

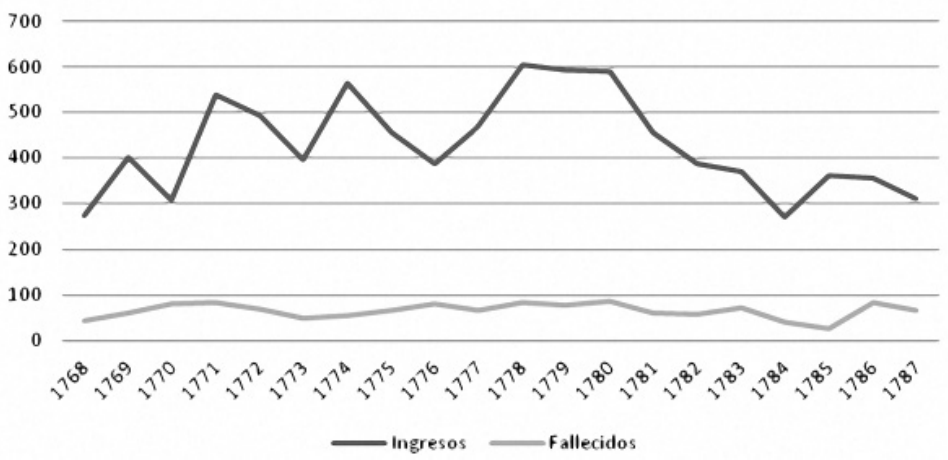

Por su parte, en la década de los ochenta, hasta donde poseemos dados, la demanda asistencial descendió notablemente, pero, tal y como se recoge en los libros de acuerdos, parece que a finales de la misma la situación volvió a complicarse. En 1789 los trabajadores pedían al patronato un aumento de suelo por «lo calamitoso del presente tiempo en pan y demás comestibles y el corto sueldo que tienen y mucho trabajo por el crecido número de enfermos». También bastante adversa debió de ser, en general, la de los noventa, pues si algún año tuvieron que recurrir a los ahorros que tenían depositados en el archivo, para afrontar la demanda asistencial, a partir de 1794 no pudieron seguir ayudando al hospital de Sotelo con la misma intensidad que lo habían hecho hasta entonces ${ }^{48}$. En 1797, en el contexto del enfrentamiento contra Inglaterra y la necesidad de reforzar las fronteras frente a su tradicional aliado, volvió a tener una elevada ocupación, en este caso de militares, lo que suponía ingresos extraordinarios, que permitieron al administrador gratificar al personal del centro con 9.000 reales - «por el trabajo que han tenido por el mayor número de enfermos el año pasado y este»-. Tres años después, de nuevo, se plantearon la necesidad de reducir el número de atenciones para no perjudicar al hospital, pero otra vez se vieron desbordados por las estancias militares ${ }^{49}$. Complicados fueron para el hospital los primeros años del siglo XIX, pues sufrieron directamente las consecuencias de las malas cosechas: falta

48. Ese año el patronato acordó cobrarle al de Sotelo el salario del médico y el valor total de las medicinas. Hasta entonces, de los 6.000 reales que más o menos debían pagar cada año, les rebajaban un tercio, pero «al presente por la carestía de alimentos y otros géneros no pueden». A.D.Z. Libros de Acuerdos del hospital de La Encarnación.

49. En 1801, en el contexto del enfrentamiento hispano-luso, esperaban en la ciudad 1.500 soldados franceses. Acordaron con el comisario de guerra que se «curarían en iguales condiciones que la tropa española y que hacienda contribuya con 6 reales por estancia». A.D.Z. Libros de Acuerdos del hospital de La Encarnación. 
de pago de los renteros y la requisa de cereal que hizo el regimiento a particulares y comunidades «para remediar las necesidades públicas». A todo ello se le añadía un aumento de la demanda asistencial.

\section{CONCLUSIONES}

El hospital de La Encarnación, concebido a comienzos del siglo XVII como un pequeño centro con garantías higiénicas y médico-sanitarias modernas, acabaría por perder el sentido original de su fundación, para convertirse en la práctica en un hospital militar. No obstante, esta nueva situación no fue en su total detrimento, sino que más bien al contrario, pues al beneficiarse de las asignaciones económicas de la corona el patronato pudo ampliar el edificio y aumentar su capacidad de respuesta.

En lo que se refiere a la trayectoria secular que experimentaron las asistencias a «paisanos» en el hospital de La Encarnación de Zamora, se observa como esa prácticamente se solapa con coyuntura económica. No en vano se trataba de un centro en el que objeto de atención eran los necesitados, cuyo volumen estaba, a su vez, estrechamente vinculado a los ciclos económicos, que cambiaban con relativa frecuencia debido a lo endeble y quebradizo de la base que los sustentaba. Por otro lado, en esa evolución, además de los ciclos económicos del ámbito provincia, se dejaron sentir con fuerza los sufridos por otros territorios, fundamentalmente por el gallego. Estas gentes llegaron a representar un tercio de los asistidos, aumentando considerablemente su presencia en momentos especialmente complicados. Circunstancia que se debería al emplazamiento geográfico de esa provincia, en la ruta seguida por los temporeros, fundamentalmente orensanos, hacia Castilla. 